\title{
Advancing Ecotoxicology in the US Southern States
}

\author{
Natàlia Garcia-Reyero ${ }^{1,2}$
}

Received: 5 May 2016/Accepted: 10 May 2016/Published online: 21 May 2016

(C) Springer Science+Business Media New York (outside the USA) 2016

The Southern states of the United States are often overlooked, but these states are home to beautiful landscapes, great culture, art, music, food, charming people and yes, great research!

This special issue of the Bulletin of Environmental Contamination and Toxicology (BECT) hosts a set of papers representing ecotoxicology research in the Mid South area of the United States. Originally, the issue started as a follow up to the Society of Environmental Toxicology and Chemistry (SETAC) MidSouth Chapter annual meeting, held in Vicksburg (MS) in May 2015. Nevertheless, other manuscripts from the Southern States have been incorporated into the Special Issue, representing a wide variety of the exciting work that is being done in this part of the United States.

In particular, this special issue is divided into three parts. The first part is focused on Understanding Toxicity, and includes five papers that use different model and non-model species to understand the effects of chemicals on wildlife and the environment. These species include the vertebrate model zebrafish (Danio rerio), a water flea (Ceriodaphnia dubia), a water snake (Nerodia sipedon), spotted salamanders

Natàlia Garcia-Reyero

Natalia.G.Vinas@erdc.dren.mil

1 Environmental Laboratory, US Army Engineer Research and Development Center, Vicksburg, MS, USA

2 Institute for Genomics, Biocomputing and Biotechnology (IGBB), Mississippi State University, Starkville, MS, USA
(Ambystoma maculatum), and two plant species (the Bermuda grass and the purple three-awn). The second part is focused on The Environment, and includes five papers that explore the presence of contaminants such as cadmium and lead in different areas of Arkansas, as well as the use of conservation practices to predict contaminants, and the effects of landscape management on nutrient mitigation. The third part focuses on New models, methods, and technologies, and includes five papers that cover computational models to predict toxicity and to understand contaminant adsorption, a novel field-screening technique for organic species, a novel treatment to destroy harmful cyanobacteria, and the development of the earthworm model for land management practices. Figure 1 illustrates the states involved in this Special Issue, as well as some of the species and environmental issues addressed.

In addition to publishing this research, I would like to stress the importance that those regional meetings have not only on networking but also on students mentoring and development. During the SETAC MidSouth Chapter meeting, seven students obtained platform or poster awards: Sarah Vogt, Amber Hills, Mary Kilmer, Shelby Chappell, Carlos Rosado-Berrios, Victoria Kremer and Lara Jarmagin. Furthermore, the fact that four students submitted manuscripts to this special issue as first authors truly highlights the importance of these regional meetings on their career development.

I would really like to thank all the authors and reviewers that contributed to this Special Issue. Also, special thanks to the Editor-in-chief of the BECT, Dr Erin Bennett, for his invaluable help and patience that really made this issue a reality. 


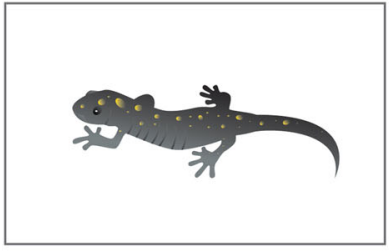

Spotted salamander

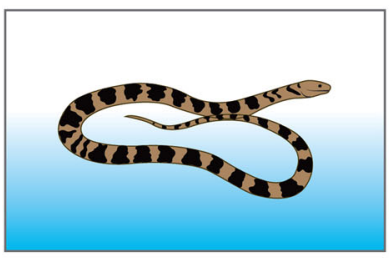

Water snake

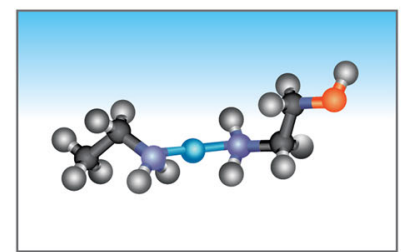

Chemical model

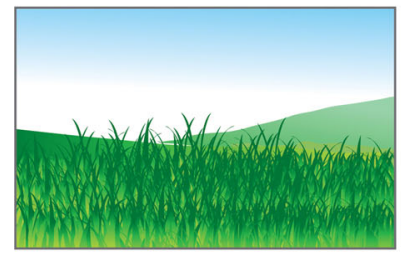

Bermuda grass
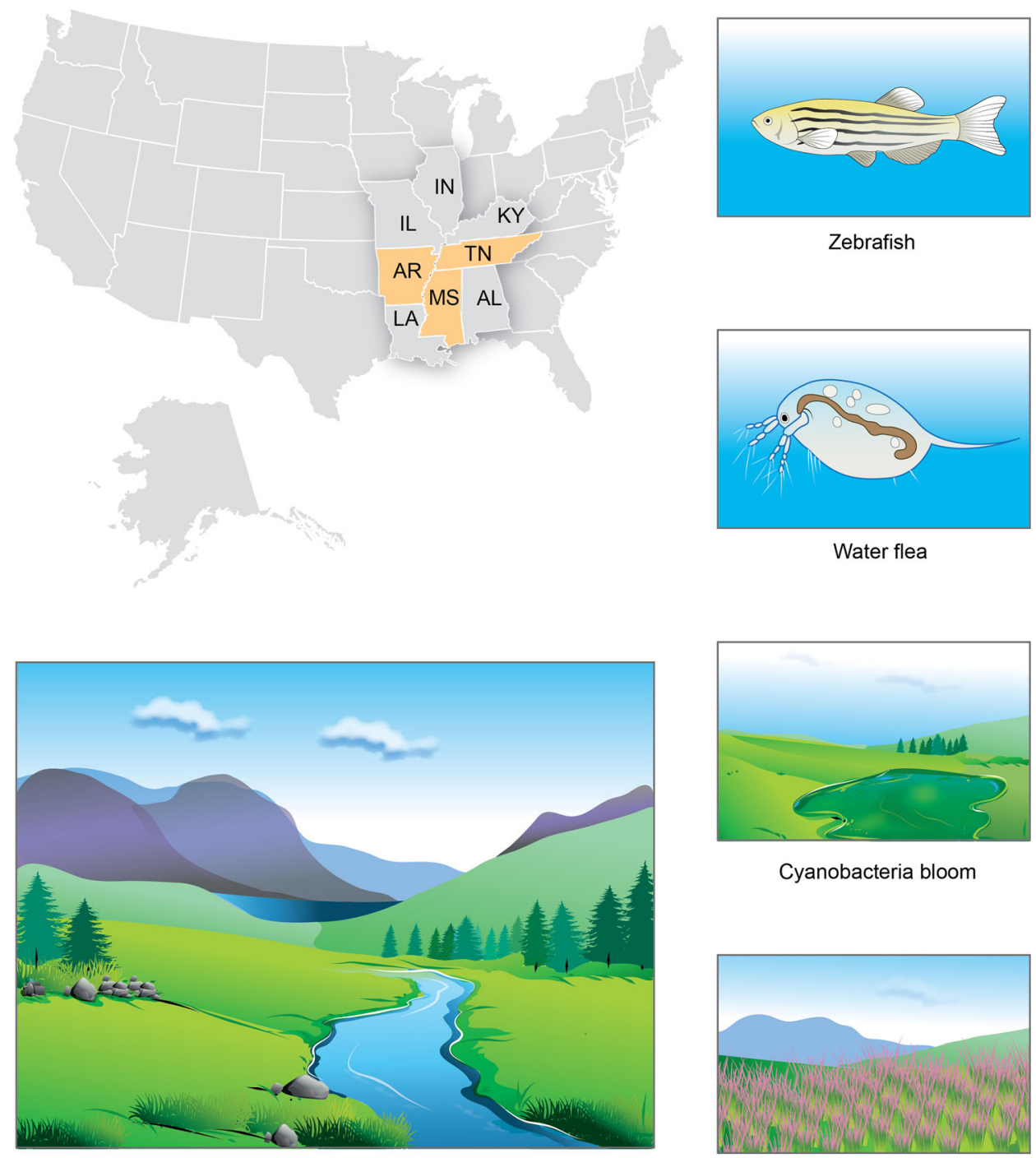

Cyanobacteria bloom

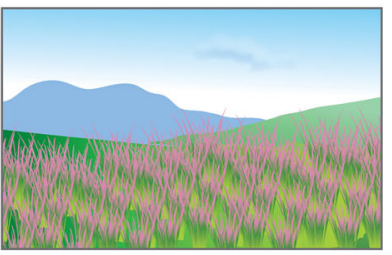

Purple three-awn

Fig. 1 Overview of the states as well as some of the species and environmental issues addressed

Finally, on behalf of myself and the contributing authors, I would like to congratulate BECT on the Journal's 50th Anniversary, as it is an honor to be part of this remarkable milestone. 